Research Paper:

\title{
The Effectiveness of Positive Thinking Training on Psychological Well-Being and Quality of Life in the Elderly
}

\author{
Soghra Safari ${ }^{1}$, Bahman Akbari ${ }^{{ }^{*}} \mathrm{Q}$ \\ 1. Department of Psychology, Rasht Branch, Islamic Azad University, Rasht, Iran.
}

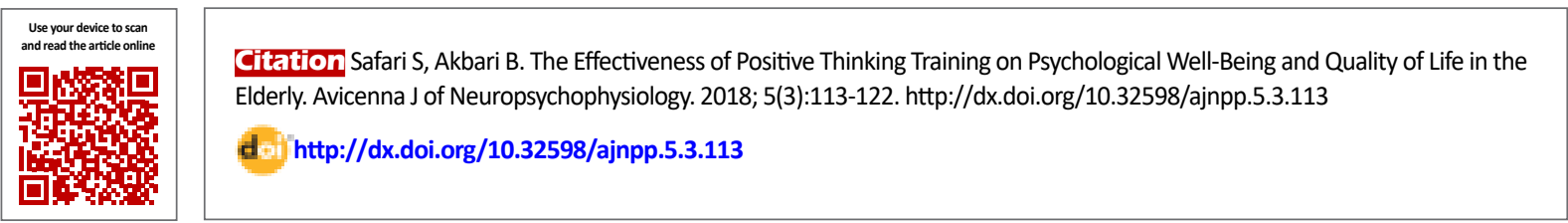

\section{(a) 03}

Article info:

Received: 13 Jan 2018

Accepted: 07 Jun 2018

Available Online: 01 Aug 2018

Keywords:

Positive thinking, Psychological well-being, Quality of life

\begin{abstract}
A B STRACT
Introduction: Nowadays, aging and its associated problems is a very important concern that has attracted the attention of different researchers with various scientific backgrounds to address this issue from various aspects.

Objectives: The aim of this study was to investigate the effectiveness of positive thinking on psychological well-being and Quality of Life (QOL) in the elderly.

Materials and Methods: This semi-experimental study was carried out with pretest-posttest design using a control group and a one-month follow-up. The statistical population consisted of 80 elderly living in nursing centers in Lahijan, Iran in 2018. In this study, 30 subjects were randomly assigned to two experimental and control groups $(n=15)$. Both groups completed the Ryff's psychological well-being inventory and the QOL questionnaire. The experimental group was also subjected to positive thinking training. Finally, the collected data were analyzed by SPSS V. 22 software using the multivariate analysis of covariance.
\end{abstract}

Results: The result showed that positive thinking training increased the scores of psychological well-being $(P<0.01)$. It also had a positive effect on the $\mathrm{QOL}$ of the experimental group compared with the control group $(\mathrm{P}<0.01)$, as it increased the $\mathrm{QOL}$ score of the experimental group, whereas the control group's score did not change.

Conclusion: According to the results of the current study, positive thinking training can increase psychological well-being and QOL in the elderly.

\section{Introduction}

$\mathrm{T}$ he population aging or the rapid rise in the number of older people is a global concern. Reduced fertility and increasing life expectancy have led to an increase in the elderly population much faster than the general population. According to the estimates, the population of people aged between 65 and 74 years will increase by $74 \%$ from 1990 to 2020. However, the increase in the popu-

\section{* Corresponding Author:}

Bahman Akbari, PhD.

Address: Department of Psychology, Rasht Branch, Islamic Azad University, Rasht, Iran

Tel: +98 (911) 1361102

E-mail: akbari@iaurasht.ac.ir 
lation of those under the age of 65 years will be 24\% [1] According to the demographic studies, aging is defined when $8 \%$ of the population is 65 years old or more, or when $12 \%$ of the population is the people aged 60 years and more. Therefore, Iran will be faced with aging in the new century [2]. Many psychological factors can affect the perseverance and promotion of the level of the elderly's health. One of the factors affecting elderly's health is the Quality of Life (QOL).

Positive psychology is a scientific study of the strengths and virtues of mankind. It represents "the average person" with an interest in understanding of his function, what is right, and what is improving. Positive psychology raises the question that "what is the nature of the beneficial human function", "how can one employ the evolved adaptations and learned skills?", and "how can psychologists explain the fact that, despite all the difficulties, most people manage their lives by maintaining their dignity and goals?".

Therefore, positive psychology is an attempt to oblige psychologists to adopt an intellectual and sympathetic viewpoint regarding capabilities, motivations and potential human capacities [3]. Positive thinking is a cognitive process to create promising imagery, expand optimistic ideas, find solutions to problems, make positive decisions, and in general, it is a clear vision of life. However, positive thinking does not ignore the need for realistic assessment. Instead, it accepts both positive and negative aspects of the issues, events, and circumstances, then moves towards focus and positive interpretation [4].

Positive thinking and seeing the beauty of the world, and even seeing ugliness from a good point of view result in using all the positive, exciting and promising mental capacities in life and never give up while facing negative thoughts created by the mind and the lack of frustration caused by the difficulty of communicating with other people and encountering nature and increases life expectancy. Positive thinking means looking at events with an assumption that although good and bad are both present in the world, but we should emphasize on goodness [5] and have a good impression of ourselves, without always putting the blames on ourselves.

It means thinking positive about others and having a good outlook on having them, and also dealing with others in a positive way. In other words, positive thinking means having a positive internal balance and keeping calm and quiet while facing problems [6]. Without a positive attitude, success is not possible; because people with positive attitudes can achieve their goals Optimists are happier than pessimists, because they focus as much as possible on the positive aspects of their tasks. It is crucial to make people informed about thinking positive in optimists [7].

Well-being has been considered by researchers for centuries, and psychological well-being, has recently been at the center of attention in one of the psychology branches called "positive psychology". Positive psychology is a scientific study of optimal human functioning. It aims to discover how human life flourishes and reaches its potentials. The psychological well-being is used as mental health in psychological studies [8]. Increasing the capacity of positive states as well as decreasing negative behaviors are defined as optimal well-being [9]. Well-being has been divided into two areas, including functional and psychological well-being [10].

Subjective well-being has two emotional and cognitive components. The emotional component is a balance between positive emotion and negative affection, whereas the cognitive component is satisfaction with life. Subjective well-being is what ordinary people call happiness [11]. In general, psychological well-being means engaging with ontological challenges and struggling for personal growth.

Today, along with an increase in longevity, QOL and how to live are of great importance. According to the definition by the World Health Organization Quality of Life (WHOQOL) Group, the QOL determines an individual's perception of his own place of residence, according to the cultural context of society and his goals, criteria, and concerns, and results from the factors, such as physical health, psychological state, independence, and social relationships [12]. QOL is related to the mental health of individuals and refers to the state of affairs and personality abilities, and also the level of people's satisfaction with living. It refers to an aspect of life representing the best state of life for the individual [13].

Most researchers believe that QOL has physical, psychological, social, and spiritual dimensions, and it is associated with the factors, such as age, culture, gender, education, social class, health, and the social environment [14]. Factors affecting QOL, such as social support has recently been considered. It has been suggested that social support plays an important role in people's health It also reduces the negative effects of the many stresses caused by the environment and the community, leading to a direct and positive impact on the QOL [15] 
To our knowledge, no research has been done on the effectiveness of positive thinking on psychological wellbeing and QOL in the elderly. The aim of this research was to investigate the effectiveness of positive thinking on psychological well-being and QOL in the elderly.

\section{Materials and Methods}

This research was a semi-experimental research with the pretest-posttest design, and a control group. The semi-experimental pretest-posttest pattern with the control group is composed of an experimental group and a matched control group. According to this design, both groups are measured two times. The statistical population consisted of the elderly living in nursing centers (80 subjects) in Lahijan, Iran in 2018. According to the type of research, 15 subjects were considered for each group selected by a random sampling method.

Among the elderly centers in Lahijan, one center was randomly selected, of which a total of 30 elderly were randomly selected and assigned into the control intervention groups ( $n=15$ for each group). The inclusion criteria were the informed consent to participate in the research, no history of using psychiatric drugs, lack of physical handicap, and those aged over 60 years. All ethical considerations were observed and the questionnaires were completed without name.

The participants were informed about the research objectives and they were encouraged to participate in the study with the possibility of withdrawing if desired. The subjects were assured of the confidentiality of information. To collect data, the researcher referred to one of the elderly centers of Rasht and provided the subjects with the psychological well-being questionnaire, QOL questionnaire as well as demographic information questionnaire, respectively.

The experimental group participated in nine sessions of positive thinking in order to increase psychological well-being and QOL, whereas the control group did not receive any training and they only participated in the pre-test phase. At the end of the training sessions, the questionnaires were distributed again among the subjects in both groups. Regarding the library information, various references, such as books, journals, articles, theses, and the websites on the Internet were used.

\section{Ryff's psychological well-being inventory}

This scale was developed by Ryff in 1989 and revised in 2002. It measures 6 factors, including autonomy, environmental mastery, personal growth, positive relationship with others, purpose in life, and self-acceptance. The total score of these six factors is calculated as the total score of psychological well-being. This test is a self-assessment instrument that is answered on a 6-degree continuum from "totally agreeable" to "totally disagreeing" (one to six).

Of all questions, 44 questions are scored directly and 40 questions are scored in a reverse manner. The correlation between the subscales was reported between 0.31 and 0.76 , with the highest correlation between self-acceptance and environmental mastery (76\%), and the lowest between autonomy and positive relationships with others $(0.32)[16,17]$. Self-acceptance was reported with a Cronbach's alpha of 0.93 , positive relations with others with 0.19 , autonomy with 0.86 , personal growth with 0.87, purpose in life with 0.90, and environmental mastery with 0.90 [18]. Also, for assessing its reliability, the Cronbach's alpha coefficient was used and obtained 0.96 for the total score of the scale.

The World Health Organization Quality of Life (WHOQOL)BREF questionnaire

This scale is the short form of the WHOQOL-100 questionnaire, developed in 1996, which has been formulated after integrating some of the domains and removing some of questions. The WHOQOL-BREF questionnaire includes 26 questions. The first two questions investigate the health status and QOL in general, and the next 24 questions examine four areas, including the physical health (7 questions), mental health (6 questions), social relationships (3 questions), and general health (8 questions).

This is scored on a 5-point Likert scale. In question 1, the QOL of the subject ranges from very bad (1) to very good (5), and in question 2, the health of the subject ranges from very dissatisfied (1) to very satisfied (5). Questions 3-9 are scored from 1 (very much) to 5 (not at all), whereas questions 10 to 14 are rated from 1 (not at all) to 5 (totally). In addition, question 15 is scored from 1 (very bad) to 5 (very good) while questions 16 to 25 are ranked from 1 (very dissatisfied) to 5 (very satisfied).

Finally, question 26 is scored from 1 (always) to 5 (never). The lowest score of the scale is 26 and the highest score is 130. A higher score indicates a better and higher QOL. Cronbach's alpha was reported 0.82 for physical health, 0.81 for mental health, 0.88 for environmental health and 0.88 for social relations [18]. To assess the reliability of the scale, three methods, including a threeweek interval (0.87), split-half (0.87), and Cronbach's 
alpha (0.87) methods were used. Also, Cronbach's alpha coefficient was used to assess the reliability of the WHOQOL-100 scale. The Cronbach's alpha coefficient for the whole scale was 0.88 , whereas for the physical health, mental health, general health, and social relations it was obtained $0.70,0.77,0.65$, and 0.77 , respectively [19].

The questionnaires were collected and the results were analyzed by SPSS-18 software using descriptive and inferential statistics. The descriptive statistics, such as frequency, percentage, central tendency and index of dispersion, and also inferential statistics, like Multivariate Analysis of Covariance (MANCOVA) were used to confirm the hypotheses.

\section{Results}

A total of 30 elderlies (15 subjects in each group) with an average age of $73.47 \pm 7.98$ and $72.67 \pm 10.15$ years for the experimental and the control groups, respectively were studied. Both groups were homogenized in terms of age (Table 1).

MANCOVA was used to investigate the positive thinking training score from the total score of the psychological well-being scale. First, the homogeneity of the regression line slope was investigated, which showed that the correlation between the components and pretest was not significant $(\mathrm{F}=6.526, \mathrm{P}<0.194)$. Therefore, the results confirmed the homogeneity of the regression slope. The assumption of the homogeneity of the errors of both groups was confirmed for the total score of the psychological well-being scale $(P<0.05)$.

MANCOVA was used to determine the effectiveness of independent variable (positive thinking) on the components of psychological well-being scale (autonomy, environmental mastery, personal growth, positive relations with others, purpose in life, and self-acceptance). First, the homogeneity of the slope of the regression line was investigated, which indicated that the correlation between the components and the pre-test was not significant $(P<0.65, F=239.4)$. As a result, the homogeneity of regression slope was confirmed. The hom ogeneity of error variance assumption in both groups was confirmed for dependent variables $(P>0.05)$.

Also, the Box's M test was used in order to study the equality of covariance matrix of dependent variables between the experimental and control groups. The F statistic for the Box's M test (1.035) were not significant $(\mathrm{F}=1.035, \mathrm{P}<0.415)$. Therefore, it can be concluded that the covariance matrix of the depende $n t$ variables is equal in the two groups. Bartlett's Chi-Square test was used to investigate the significant correlation between psychological well-being componen $\mathrm{t} s$ and obtained 151.460, which was significant at the level of 0.001 . Accordingly, MANCOVA was used.

According to Table 2, the F statistic for MANCOVA regarding the difference between the experimental and control groups in the components of psychological well-being was statistically significant (Wilks' lambda= $0.368, F=4.863$, and $P<0.001$ ). Therefore, it can be concluded that there was a significant difference between the experimental and control groups at least in one of the components of psychological well-being scale in the post-test after adjustment for the pre-test scores and the interaction between the components of psychological well-being scale. Table 3 shows the effects of the components of psychological well-being scale.

The inter-group results showed that after adjustment for the pre-test scores, the effect of positive thinking training on improving the autonomy $(F=25.255, d f=1$, $P<0.001)$, environmental mastery $(F=8.431, d f=1$, $\mathrm{P}<0.008)$, personal growth $(\mathrm{F}=7.982, \mathrm{df}=1, \mathrm{P}<0.010)$, purpose in life $(F=8.246, d f=1, P<0.009)$, and self-acceptance $(\mathrm{F}=11.409, \mathrm{df}=1, \mathrm{P}<0.003$ ) was significant. It can be concluded that the mean score of the experimental group in autonomy, environmental mastery, personal growth, purpose in life, and self-acceptance was significantly higher than the control group. Therefore, using positive thinking training is effective on the components, including autonomy, environmental mastery, personal growth, purpose in life, and self-acceptance of the elderly.

MANCOVA was used to determine the effectiveness of the independent variable (positive thinking) on QOL components (physical health, mental health, social relations, and general health). At first, the homogeneity of the regression line slope was investigated, which indicated that the interaction between the components and the pre-test was not significant ( $F=2.296$, $\mathrm{P}<0.347)$. Therefore, the homogeneity of the regression line slope was confirmed.

The homogeneity of error variance assumption of both groups was confirmed for dependent variables $(P<0.05)$. The $F$ statistic of the Box's M test (23.2929) was not significant $(F=2.019, P<0.028)$. Therefore, it can be concluded that the covariance matrix of the dependent variables was equal in the two groups. Bartlett's Chi-Square test was used to assess the significant cor- 
Table 1. Descriptive indices of the study variables and the coefficients of Skewness and Kurtosis in the experimental and control groups

\begin{tabular}{|c|c|c|c|c|c|}
\hline Variable & Stage & Group & Mean士SD & Skewness & Kurtosis \\
\hline \multirow{4}{*}{ Psychological well-being total score } & \multirow{2}{*}{ Pre-test } & Experimental & $332.73 \pm 57.74$ & -0.140 & -0.679 \\
\hline & & Control & $304.06 \pm 65.12$ & -0.296 & 0.820 \\
\hline & \multirow{2}{*}{ Post-test } & Experimental & $380.33 \pm 42.99$ & -0.429 & -0.392 \\
\hline & & Control & $298.26 \pm 52.98$ & 0.106 & -0.548 \\
\hline \multirow{4}{*}{ Autonomy } & \multirow{2}{*}{ Pre-test } & Experimental & $51.60 \pm 8.03$ & -0.818 & -0.391 \\
\hline & & Control & $46.80 \pm 5.90$ & -0.574 & -0.836 \\
\hline & \multirow{2}{*}{ Post-test } & Experimental & $56.20 \pm 6.79$ & -0.499 & -0.812 \\
\hline & & Control & $43.80 \pm 5.72$ & -0.413 & -0.111 \\
\hline \multirow{4}{*}{ Environmental mastery } & \multirow{2}{*}{ Pre-test } & Experimental & $55.40 \pm 11.96$ & 0.188 & 0.154 \\
\hline & & Control & $49.26 \pm 15.46$ & 0.749 & -0.299 \\
\hline & \multirow{2}{*}{ Post-test } & Experimental & $65.13 \pm 8.55$ & 0.343 & -0.167 \\
\hline & & Control & $50.00 \pm 12.02$ & -0.202 & -0.639 \\
\hline \multirow{4}{*}{ Personal growth } & \multirow{2}{*}{ Pre-test } & Experimental & $57.93 \pm 12.44$ & 0.472 & -0.643 \\
\hline & & Control & $53.26 \pm 12.34$ & 0.121 & -0.372 \\
\hline & Pect-tect & Experimental & $64.93 \pm 9.00$ & 0.705 & -0.106 \\
\hline & POSt-test & Control & $50.93 \pm 11.60$ & 0.364 & -1.204 \\
\hline \multirow{4}{*}{ Positive relationships } & \multirow{2}{*}{ Pre-test } & Experimental & $59.86 \pm 11.57$ & -0.868 & 1.488 \\
\hline & & Control & $59.13 \pm 13.33$ & -0.131 & -1.442 \\
\hline & \multirow{2}{*}{ Post-test } & Experimental & $68.00 \pm 8.22$ & 0.355 & -1.206 \\
\hline & & Control & $61.66 \pm 6.55$ & -0.258 & -1.115 \\
\hline \multirow{4}{*}{ Purpose in life } & \multirow{2}{*}{ Pre-test } & Experimental & $55.72 \pm 14.93$ & -0.493 & -0.824 \\
\hline & & Control & $49.33 \pm 17.53$ & -0.151 & -0.194 \\
\hline & \multirow{2}{*}{ Post-test } & Experimental & $63.73 \pm 11.06$ & 0.931 & 2.119 \\
\hline & & Control & $45.80 \pm 13.45$ & 0.782 & 0.214 \\
\hline \multirow{4}{*}{ Self-acceptance } & \multirow{2}{*}{ Pre-test } & Experimental & $52.20 \pm 11.32$ & -0.633 & 0.048 \\
\hline & & Control & $46.26 \pm 13.92$ & -0.353 & -0.878 \\
\hline & Post-test & Experimental & $62.33 \pm 8.11$ & -0.449 & 0.435 \\
\hline & POSt-test & Control & $46.06 \pm 11.98$ & -0.656 & 0.905 \\
\hline \multirow{4}{*}{ Total score of Life quality } & \multirow{2}{*}{ Pre-test } & Experimental & $66.00 \pm 7.36$ & -1.034 & 0.459 \\
\hline & & Control & $70.33 \pm 5.80$ & -0.755 & -0.751 \\
\hline & \multirow{2}{*}{ Post-test } & Experimental & $80.00 \pm 6.24$ & -0.316 & -1.167 \\
\hline & & Control & $72.13 \pm 6.02$ & -0.112 & -0.504 \\
\hline & Pre_tect & Experimental & $23.06 \pm 3.39$ & 0.642 & -0.699 \\
\hline Phvcical health & rie-tess & Control & $24.26 \pm 2.54$ & -1.267 & 1.398 \\
\hline Physical nealth & Post-te & Experimental & $24.80 \pm 4.53$ & -0.598 & -0.106 \\
\hline & POSt-test & Control & $24.66 \pm 2.76$ & -0.349 & -0.415 \\
\hline & & Experimental & $18.06 \pm 1.03$ & 0.070 & -0.379 \\
\hline Mental health & Pre-test & Control & $18.33 \pm 2.16$ & 0.521 & -0.638 \\
\hline IVierilar tiediut & Post-test & Experimental & $22.20 \pm 1.69$ & 0.164 & -0.146 \\
\hline & POSt-test & Control & $18.86 \pm 1.95$ & 0.653 & -0.416 \\
\hline & Pre_tect & Experimental & $7.06 \pm 1.86$ & -0.934 & 0.982 \\
\hline Social relationchinc & rie-tess & Control & $7.93 \pm 1.62$ & 0.094 & -0.691 \\
\hline social relationshıps & Post & Experimental & $9.60 \pm 1.63$ & -0.458 & -0.590 \\
\hline & POSt-test & Control & $8.40 \pm 1.59$ & -0.843 & -0.106 \\
\hline & & Experimental & $17.80 \pm 3.60$ & -0.206 & -0.915 \\
\hline Envirenment health & Pre-tes & Control & $19.80 \pm 2.33$ & 0.214 & -0.825 \\
\hline 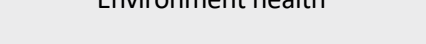 & Post-test & Experimental & $23.40 \pm 3.112$ & 0.454 & 0.577 \\
\hline & POSt-test & Control & $20.20 \pm 2.177$ & -0.247 & -0.175 \\
\hline
\end{tabular}


Table 2. Results of the multivariate analysis of covariance (MANCOVA) for the psychological well-being components between the control and experiment groups

\begin{tabular}{ccccc}
\hline Test & Values & F & Degree of Freedom1 & Degree of Freedom1 \\
\hline Pillai's Trace & 0.632 & & & \\
Wilks' lambda & 0.368 & 4.863 & & \\
Hotelling's trace Roy's Largest & 1.617 & & & \\
Root & 1.716 & & \\
\hline
\end{tabular}

AJNPP

Table 3. Effects of components of psychological well-being scale using Multivariate Analysis of Covariance (MANCOVA) after adjustment for the pre-test scores and post-test analysis

\begin{tabular}{|c|c|c|c|c|c|c|}
\hline Variables & Sum of Squares & $\begin{array}{l}\text { Degree of } \\
\text { Freedom }\end{array}$ & $\begin{array}{l}\text { Mean of } \\
\text { Squares }\end{array}$ & $\mathbf{F}$ & $\mathbf{P}$ & $\begin{array}{l}\text { Eta Coeffi- } \\
\text { cient }\end{array}$ \\
\hline Autonomy & 659.287 & 1 & 659.287 & 25.235 & 0.001 & 0.534 \\
\hline Environmental mastery & 934.369 & 1 & 934.369 & 8.431 & 0.008 & 0.277 \\
\hline Personal growth & 936.921 & 1 & 936.921 & 7.982 & 0.010 & 0.266 \\
\hline Positive relationship with others & 245.698 & 1 & 245.698 & 4.158 & 0.054 & 0.054 \\
\hline Purpose in life & 1442.045 & 1 & 1442.045 & 8.269 & 0.009 & 0.273 \\
\hline Self-acceptance & 1176.882 & 1 & 1176.882 & 11.409 & 0.003 & 0.341 \\
\hline
\end{tabular}

AJNPP

relation between the components of $\mathrm{QOL}$ and was obtained 422.42, which was significant at the level of 0.001 . Therefore, there was a significant relationship between these components. Accordingly, a MANCOVA was used.

According to Table 4, the F statistic for MANCOVA regarding the difference between the experimental and control groups in the components of QOL was significant at the level of 0.001 (Wilks' Lambda $=0.109, F=42.715$, $\mathrm{P}<0.001)$. Therefore, it can be concluded that there was a significant difference between the experimental and control groups in at least one of the components of QOL in the post-test after adjustment for the pre-test scores and the interaction between the components of QOL. The results of the inter-group comparison regarding the components of QOL scale are presented in Table 5.

As shown in Table 5, the results of inter-group comparison showed that after adjustment for the pre-test scores, the effect of positive thinking training on improving the, mental health $(F=0.077 .751, d f=1, P<0.001)$, social relations $(F=33.217, d f=1, P<0.001)$, and environmental health $(F=49.306, d f=1, P<0.001)$, scores was

Table 4. Results of the Multivariate analysis of covariance (MANCOVA) of the components of the quality of life questionnaire among the control and experimental groups

\begin{tabular}{|c|c|c|c|c|c|}
\hline Test & Values & $\mathbf{F}$ & Degree of Freedom 1 & $\begin{array}{l}\text { Degree of Free- } \\
\text { dom1 }\end{array}$ & $\mathbf{P}$ \\
\hline Pillai's Trace & 0.891 & \multirow{5}{*}{42.715} & \multirow{5}{*}{4} & \multirow{5}{*}{21} & \multirow{5}{*}{0.001} \\
\hline Wilks' lambda & 0.109 & & & & \\
\hline & & & & & \\
\hline Hotelling's trace & 8.136 & & & & \\
\hline Roy's Largest Root & 8.136 & & & & \\
\hline
\end{tabular}


Table 5. Results of inter-group comparison by Multivariate Analysis of Covariance (MANCOVA) after adjustment for the pre-test and posttest analysis of the quality of life scale components in the experimental and control groups

\begin{tabular}{cccccc}
\hline \multicolumn{1}{c}{ Variables } & Sum of Squares & Degree of Freedom & $\begin{array}{c}\text { Mean of } \\
\text { Squares }\end{array}$ & F & Pta Coefficient \\
\hline Psychical health & 6.287063 & 1 & 6.063 & 1.933 & 0.177 \\
\hline Environmental mastery & 93.982 & 1 & 93.982 & 77.751 & 0.001 \\
\hline Social relationships & 23.929 & 1 & 23.929 & 33.217 & 0.001 \\
Environmental health & 143.224 & 1 & 143.224 & 49.306 & 0.001 \\
\hline
\end{tabular}

significant. It can be said that the mean score of the experimental group in mental health, social relations and environmental health was significantly higher than the control group. Accordingly, it can be concluded that using positive thinking training was effective in improving the components, including mental health, social relations, and the environmental health of the elderly.

\section{Discussion}

The results of this study showed that the mean scores of the experimental group in the components, including autonomy, environmental mastery, personal growth, purpose in life, and self-acceptance were significantly higher than the control group. Accordingly, it can be argued that using positive thinking training is effective on the autonomy, environmental domination, personal growth, purpose in life, and self-acceptance of the elderlies. This finding was consistent with the results of studies by Johnston [20] and Myles et al. [21].

In explaining this finding, it can be said that positive psychology, as a new approach in psychology, focuses on the understanding and description of happiness and mental feeling of well-being, as well as the precise prediction of the factors affecting them. From the positive psychology' perspective, the absence of signs of mental illness is not an indicator for health. However, compatibility, happiness and self-esteem, and other positive emotional factors have been considered as indicators for health. The main purpose of an individual in his life is to flourish his own capabilities. Therefore, positive thinking-oriented psychologists emphasize the existence of positive features and the development of individual abilities and consider the person's positive mental aspect. Psychological capital is one of the indicators for positive psychology, which has been defined by characteristics, such as an individual's belief in his/ her own ability to achieve success, having perseverance in pursuing aims and goals, creating positive attributes about himself, and tolerating problems [22]

Positive capacities and experiences, like satisfaction with life are among the pivotal aspects of positive psychology [20]. One of the basic concepts in the positive psychology movement, which is one of the new branches of psychology, is psychological well-being. Positive psychology has opened up a new horizon to psychologists and researchers. In positive psychology, psychology is used to recognize and promote positive aspects and strengths of the man, rather than putting emphasis on identifying and studying mental deficits and behavioral deficiencies and restoring or treating them [21].

Positive psychology training is an effective way to increase the abilities and QOL of individuals. The high prevalence of depression throughout the world has led to a decrease in QOL and life satisfaction. Positive psychology training increased happiness, positive feelings, meaningfulness and commitment to life in individuals [22]. In positive psychology training, a set of skills needed to succeed in life is taught to the person and helps him develop the abilities, information, orientations, and skills necessary for a healthy and successful life. Ultimately, these factors increase the QOL of the elderly. Positive psychology training during the sessions led to an increase in the scores of well-being and QOL in the elderly.

The statistical population of this research was only composed of the elderlies. The higher number of questions could have resulted in fatigue and error in responding the questionnaires. Due to the unwillingness of some subjects, the questionnaires could not be completed without the researcher's assistance. In Iran, especially in the elderly population, attention has been given to a successful life and the existence of a high standard of living and well-being. Therefore, the subjects may have refrained from expressing their exact 
and actual rate of well-being, or they may have tried to report their higher level of well-being.

Because of the high number of questions, it was not possible for the subjects to answer the research questions without the researcher's assistance. Therefore, after providing the necessary explanations, the questionnaires were distributed among the subjects to be filled in their free time. Therefore, it was not possible for the researcher to monitor the accuracy of the answers to the questions. Perhaps interviewing with an unknown interviewer to the subjects and also adherence to the rituals by the participants to introduce themselves with a high standard of well-being and QOL led to provide undesirable and false answers to the questions.

It is suggested to conduct further studies on various statistical populations, such as young people, couples, and other groups. It is suggested that in studies on the elderly, the research methods should be developed in order to collect data or analyze them in a qualitative or content analysis manner or to employ longitudinal studies to determine the rate of individuals' well-being and QOL. To obtain more precise and error-free results, more objective methods should be used to evaluate the data. It is suggested to conduct relevant studies in other cities on different samples in order to increase the generalizability of the results. Many factors are effective on the QOL and well-being of the elderly. Therefore, it is suggested that in other studies, other therapeutic methods, such as mindfulness-based cognitive therapy, acceptance and commitment therapy, metacognitive therapy, etc. be considered.

It is recommended that this study be carried out on a larger sample size, so that the hypotheses are more strongly rejected or approved. Organizing positive thinking training courses in order to familiarize other elderly, especially married elderly, to increase well-being and QOL, conducting psychological assessments of the elderly to identify and take preventive measures, positive psychology training for young people should also be considered. These measures can be effective to provide a happier life among the elderly.

According to the results of the current study, positive thinking training can increase psychological well-Being and QOL in the elderly. No research has yet been done on the efficacy of positive thinking on psychological well-being and QOL in the elderly, which is the strength of the present research. It is suggested that positive thinking training must be the priority of clinical inter- ventions in order to increase the psychological wellbeing and QOL.

\section{Ethical Considerations}

\section{Compliance with ethical guidelines}

All ethical principles were considered in this research. The participants were informed about the research objectives and its stages and signed the informed consent. They were also assured of the confidentiality of their information. Moreover, the subjects were allowed to withdraw from the study whenever they wish, and if desired, the results of the research would be available to them.

\section{Funding}

This research did not receive any specific grant from funding agencies in the public, commercial, or not-forprofit sectors.

\section{Authors' contributions}

All authors contributed equally in preparing all parts of the research.

\section{Conflict of interest}

The authors declared no conflict of interest.

\section{References}

[1] Bekhet AK, Zauszniewski JA. Measuring use of positive thinking skills: Psychometric testing of a new scale. Western Journal of Nursing Research. 2013; 35(8):1074-93. [DOI:10.1177\% 2F0193945913482191] [PMID]

[2] Backhaus $P$, editor. Communication in elderly care: Cross-cultural perspectives. London: Bloomsbury Publishing; 2011. https://books. google.com/books?id=2WQSBWAAQBAJ\&dq

[3] Brandstätter M, Baumann U, Borasio GD, Fegg MJ. Systematic review of meaning in life assessment instruments. Psycho-Oncology. 2012; 21(10):1034-52. [DOI:10.1002/pon.2113] [PMID]

[4] Emek-Savaş DD, Güntekin B, Yener GG, Başar E. Decrease of delta oscillatory responses is associated with increased age in healthy elderly. International Journal of Psychophysiology. 2016; 103:103-9. [DOI:10.1016/j.ijpsycho.2015.02.006] [PMID]

[5] Froman L. Positive psychology in the workplace. Journal of Adult Development. 2010; 17(2):59-69. [DOI:10.1007/s10804-009-9080-0]

[6] Bakas T, McLennon SM, Carpenter JS, Buelow JM, Otte JL, Hanna KM, et al. Systematic review of health-related quality of life 
models. Health and Quality of Life Outcomes. 2012; 10:134. [DOI:10.1186/1477-7525-10-134] [PMID] [PMCID]

[7] Jung JY, Oh YH, Oh KS, Suh DW, Shin YC, Kim HJ. Positive-thinking and life satisfaction amongst Koreans. Yonsei Medical Journal. 2007; 48(3):371-8. [DOI:10.3349/ymj.2007.48.3.371] [PMID] [PMCID]

[8] Lee FS, Heimer H, Giedd JN, Lein ES, Šestan N, Weinberger DR, et al. Mental health. Adolescent mental health--opportunity and obligation. Science. 2014; 346(6209):547-9. [DOI:10.1126/science.1260497] [PMID] [PMCID]

[9] Tanjani PT, Motlagh ME, Nazar MM, Najafi F. The health status of the elderly population of Iran in 2012. Archives of Gerontology and Geriatrics. 2015; 60(2):281-7. [DOI:10.1016/j.archger.2015.01.004] [PMID]

[10] Shoshani A, Steinmetz S. Positive psychology at school: A schoolbased intervention to promote adolescents' mental health and well-being. Journal of Happiness Studies. 2014; 15(6):1289-311. [DOI:10.1007/s10902-013-9476-1]

[11] Gordeeva TO, Osin EN. Optimistic attributional style as a predictor of well-being and performance in different academic settings. In: Brdar I, editor. The Human Pursuit of Well-Being. Dordrecht: Springer; 2011. [DOI:10.1007/978-94-007-1375-8_14]

[12] Ryff CD. Psychological well-being revisited: Advances in the science and practice of eudaimonia. Psychotherapy and Psychosomatics. 2014; 83(1):10-28. [DOI:10.1159/000353263] [PMID] [PMCID]

[13] Boylan JM, Ryff CD. Psychological well-being and metabolic syndrome: Findings from the MIDUS national sample. Psychosomatic Medicine. 2015; 77(5):548-58. [DOI:10.1097/ PSY.0000000000000192] [PMID] [PMCID]

[14] Gillham J, Adams-Deutsch Z, Werner J, Reivich K, Coulter-Heind $\mathrm{V}$, Linkins $\mathrm{M}$, et al. Character strengths predict subjective well-being during adolescence. The Journal of Positive Psychology. 2011; 6(1):31-44. [DOI:10.1080/17439760.2010.536773]

[15] Hart KE, Sasso T. Mapping the contours of contemporary positive psychology. Canadian Psychology/Psychologie Canadienne. 2011; 52(2):82-92. [DOI:10.1037/a0023118]

[16] Seligman ME, Steen TA, Park N, Peterson C. Positive psychology progress: Empirical validation of interventions. American Psychologist. 2005; 60(5):410-21. [DOI:10.1037/0003-066X.60.5.410] [PMID]

[17] Huppert FA, So TT. Flourishing across Europe: Application of a new conceptual framework for defining well-being. Social Indicators Research. 2013; 110(3):837-61. [DOI:10.1007/s11205-011-9966-7] [PMID] [PMCID]

[18] Diener E, Chan MY. Happy people live longer: Subjective well-being contributes to health and longevity. Applied Psychology: Health and Well-Being. 2011; 3(1):1-43. [DOI:10.1111/j.17580854.2010.01045.x]

[19] Diener E, Heintzelman SJ, Kushlev K, Tay L, Wirtz D, Lutes LD, et al. Findings all psychologists should know from the new science on subjective well-being. Canadian Psychology/Psychologie Canadienne. 2017; 58(2):87-104. [DOI:10.1037/cap0000063]

[20] Johnstone J, Rooney RM, Hassan Sh, Kane RT. Prevention of depression and anxiety symptoms in adolescents: 42 and 54 months follow-up of the Aussie Optimism Program-Positive Thinking Skills. Frontiers in Psychology. 2014; 5:364. [DOI:10.3389/fpsyg.2014.00364]

[21] Myles-Pallister JD, Hassan Sh, Rooney RM, Kane RT. The efficacy of the enhanced Aussie Optimism Positive Thinking Skills Program in improving social and emotional learning in middle childhood. Frontiers in Psychology. 2014; 5:909. [DOI:10.3389/fpsyg.2014.00909] [PMID] [PMCID]

[22] Waters AJ, Szeto EH, Wetter DW, Cinciripini PM, Robinson JD, Li Y. Cognition and craving during smoking cessation: An ecological momentary assessment study. Nicotine \& Tobacco Research. 2014 16(Suppl. 2):S111-S8. [DOI:10.1093/ntr/ntt108] [PMID] [PMCID] 
